\title{
O protagonismo de organizações indígenas na estruturação da cadeia produtiva da castanha-da-amazônia no estado de Roraima, Amazônia brasileira
}

\author{
The protagonism of indigenous organizations in the structuring of the Brazil nut \\ production chain in the State of Roraima, Brazilian Amazon
}

\section{El papel de las organizaciones indígenas en la estructuración de la cadena de producción de la nuez amazónica en el estado de Roraima, Amazonía brasileña}

\author{
Julianna Fernandes Maroccolo ${ }^{1}$ \\ Lúcia Helena de Oliveira Wadt ${ }^{2}$ \\ Janaína Deane de Abreu Sá Diniz ${ }^{3}$ \\ Kátia Emídio da Silva²
}

Recebido em: 08/11/2019; revisado e aprovado em 05/03/2020; aceito em 11/03/2020. DOI: http://dx.doi.org/10.20435/inter.v22i1.2816

\begin{abstract}
Resumo: Roraima é o estado brasileiro com menor produção de castanha-da-amazônia entre aqueles onde há ocorrência da espécie. Com uma área notavelmente menor que os demais estados da região e diante da ocorrência de castanhais restritos à porção centro-sul do seu território, a produção dessa castanha em Roraima aparece pequena nas estatísticas oficiais. No entanto os dados oficiais, além de ignorarem a quantidade de castanha escoada sem controle para outras regiões, desconsideram a importância econômica, social e histórico-cultural que esse produto pode ter para as centenas de famílias que vivem de sua produção no estado. De acordo com um mapeamento da cadeia produtiva da castanha realizado em Roraima, foi possível construir um retrato da situação de sua produção e comercialização nos anos de 2013 e 2014, quando se formou uma articulação em prol da estruturação dessa cadeia no estado, especialmente no tocante à produção oriunda dos povos indígenas Wai Wai e Yanomami. Embora os indígenas Wai Wai comercializassem a castanha há mais tempo, com mais organizações de apoio e uma cadeia mais estruturada, tanto eles como os Yanomami tinham a maior parte desse apoio direcionado à produção de castanha. Isso explica o fato de a comercialização ter se mostrado como sendo o elo mais frágil e com maior demanda de investimentos. Sendo assim, diante do potencial produtivo das Terras Indígenas e da maior valorização da atividade e do próprio produto, a falta de planejamento para a coleta e a venda coletiva, assim como a necessidade de investimentos em infraestrutura de escoamento e beneficiamento, apresentam-se como importantes gargalos à organização dos povos indígenas em torno da cadeia produtiva da castanha-da-amazônia em Roraima.
\end{abstract}

Palavras-chave: Bertholletia excelsa; Wai Wai; Yanomami; organizações indígenas.

Abstract: Roraima is the Brazilian state with the lowest Amazon nut production. With an area smaller than other states in the Amazon region and due to the occurrence of the Brazil nut stands restricted to the south-central portion of its territory, the production of this nut in Roraima appears small in official statistics. However, official data ignore the nuts uncontrolled sold to other regions and disregards the economic, social, and historical-cultural importance that this product may have for the hundreds of families living on Brazil nut production in the state. According to a mapping of the Brazil nut production chain in Roraima, it was possible to construct a picture about the situation of its production and marketing in 2013 and 2014, when an articulation was formed in favor of the structuring of this chain in the state, especially regarding the indigenous peoples Wai Wai and Yanomami production. Although the Wai Wai people traded the nut for a longer time, with more support organizations and a more structured chain, both they and the Yanomami had most of this support directed to the nut production. This explains the fact that commercialization has proved to be the weakest link with the highest investment demand. Thus, given the productive potential of the Indigenous Lands and the greater appreciation of the activity and the product itself, the lack of planning for collection and collective sale, as well as the need for investments in outflow and processing infrastructure, are important bottlenecks to the organization of indigenous peoples around Brazil nut production chain in the state of Roraima.

\footnotetext{
${ }^{1}$ Instituto Nacional de Pesquisas da Amazônia (Inpa), Manaus, Amazonas, Brasil.

2 Empresa Brasileira de Pesquisa Agropecuária (Embrapa), Porto Velho, Rondônia, Brasil.

${ }^{3}$ Universidade de Brasília (UNB), Brasília, Distrito Federal, Brasil.
} 
Keywords: Bertholletia excelsa; Wai Wai; Yanomami; indigenous organizations.

Resumen: Roraima es el estado brasileño con la más baja producción de nuez amazónica entre aquellos donde se encuentra la especie. Con un área notablemente más pequeña que otros estados de la región y debido a la presencia de esa nuez ser únicamente en la parte centro-sur de su territorio, la producción de esta nuez en Roraima parece pequeña en las estadísticas oficiales. Sin embargo, los datos oficiales, además de ignorar la cantidad distribuida sin control que se vende a otras regiones, ignoran la importancia económica, social e histórico-cultural que ese producto puede tener para los cientos de familias que viven de su producción en el estado. Según un mapeo de su cadena de producción realizado en Roraima, fue posible construir una imagen de la situación de su producción y comercialización en los años de 2013 y 2014, cuando se formó una articulación a favor de la estructuración de esta cadena en el estado, especialmente con respecto a la producción de los pueblos indígenas Wai Wai y Yanomami. Aunque los Wai Wai comercializan la nuez por más tiempo, con más organizaciones de apoyo y una cadena más estructurada, tanto ellos como los Yanomami tenían la mayor parte de este apoyo dirigido a la producción de nuez. Esto explica el hecho de que la comercialización ha demostrado ser el eslabón más débil con la mayor demanda de inversión. Por lo tanto, dado el potencial productivo de las tierras indígenas y la mayor apreciación de la actividad y del producto en sí, la falta de planificación para la recolección y la venta colectiva, así como la necesidad de inversiones en la distribución y la infraestructura de procesamiento, son importantes puntos de atención en la organización de los pueblos indígenas sobre la cadena de producción de nuez amazónica en Roraima.

Palabras claves: Bertholletia excelsa; Wai Wai; Yanomami; organizaciones indígenas.

\section{INTRODUÇÃO}

A maior parte da produção comercializada da castanha-da-amazônia ${ }^{4}$ (Bertholletia excelsa Bonpl.) vem sendo liderada por três estados da região Norte. De acordo com os dados oficiais, os estados do Acre, Amazonas e Pará respondem por mais de $80 \%$ da produção nacional de castanha-da-amazônia, variando de 83\% a 91\% entre 2010 e 2017 (IBGE, 2019). O último estado nesse ranking é Roraima, que, nesse mesmo período, teve registrada uma produção que variou de 105 t em 2011 a 380 t em 2017. Embora a produção de Roraima seja pequena, a castanha é o produto florestal que apresenta a maior regularidade de produção desde 1920 e, ao contrário da sorva, balata, borracha, cacau e do buriti, também é o único que tem se mantido no registro dos censos de Roraima (BRASIL, 2009).

Sabe-se que parte da castanha de Roraima tem sido escoada para outros estados, especialmente para o Amazonas, por meio da rodovia BR-174, que liga Manaus e Boa Vista (observação de campo). Por outro lado, além de a produção ser restrita às florestas nativas com castanhais, Roraima é um dos menores estados da Amazônia brasileira, com área de ocorrência da castanheira restrita a $54 \%$ do estado (INPE, 2015). Sendo assim, os principais municípios produtores de castanha são aqueles localizados no centro-sul de Roraima, mais especificamente Rorainópolis, Caracaraí, São João da Baliza, Caroebe e São Luíz do Anauá.

Esses cinco municípios produtores de castanha compõem o chamado Território da Cidadania Sul de Roraima e, entre 2003 e 2014, receberam uma atenção especial nas ações do Governo Federal em termos de redução das desigualdades sociais e superação da extrema pobreza. Com uma área de aproximadamente 99 mil km², esse território contém uma população de mais de 64 mil habitantes, sendo que aproximadamente metade desses vive em zona rural (BRASIL, 2015).

Além das famílias assentadas e dos povos de cinco diferentes Terras Indígenas, o território é ocupado por agricultores familiares e extrativistas. De modo geral, são famílias que têm como

\footnotetext{
${ }^{4}$ Também conhecida como castanha-do-pará e castanha-do-brasil, em 2008, o Ministério da Agricultura, Pecuária e Abastecimento registrou o nome comum da espécie como castanha-da-amazônia (registro n. 23550). Portanto adotou-se neste documento o nome castanha-da-amazônia.
} 
fonte de renda produtos típicos da agricultura familiar, como a farinha, a banana e o abacaxi, sendo que o perfil dos produtores de castanha parece diferir em relação ao regime de uso da terra. Enquanto existe uma tendência de os castanheiros que vivem em assentamentos terem sua origem em outras regiões e terem iniciado mais recentemente a coleta de castanha, as famílias ribeirinhas do Baixo Rio Branco tendem a ser naturais da região e a praticarem tradicionalmente a coleta da castanha (TONINI et al., 2006, TONINI; BORGES, 2010).

Apesar de a produção de castanha ser pequena em relação aos outros estados, existe nela uma significativa importância econômica e histórico-cultural para a população local. Com o intuito de retratar a importância da cadeia produtiva da castanha em Roraima, no âmbito do Projeto MapCast, projeto desenvolvido pela Embrapa com o intuito de realizar um Mapeamento de Castanhais Nativos e a Caracterização Socioambiental e Econômica de Sistemas de Produção da Castanha-do-Brasil na Amazônia, foi realizado em 2014 um mapeamento dessa cadeia, buscando identificar as organizações envolvidas e as principais características dos produtores, da produção e dos canais de sua comercialização no estado.

Existem poucos trabalhos científicos que tratem da produção e comercialização de castanha pelos povos indígenas de Roraima. Diante dessa lacuna de informações, o presente artigo tem o intuito de fornecer uma descrição sistemática de como a cadeia produtiva da castanha em Roraima vinha se estruturando até 2014, época do estudo, dando ênfase à participação dos povos indígenas nesse processo. Ao descrever a emergência das organizações indígenas na cadeia produtiva da castanha, este documento também aborda sobre os principais avanços, as problemáticas enfrentadas e as possíveis soluções do ponto de vista dos envolvidos nessa cadeia produtiva.

\section{METODOLOGIA}

Para se obter um retrato de como estava estruturada a cadeia produtiva da castanha em Roraima em 2014, foi feita uma pesquisa na internet em busca de publicações e notícias relacionadas ao tema. Dessa maneira, foi possível obter as primeiras referências de quais comunidades estavam organizadas e desenvolvendo projetos e ações com castanha no estado. Não foram considerados os produtores e extrativistas individualizados, uma vez que esta parte da cadeia já foi caracterizada em outros estudos (TONINI et al., 2006; TONINI; BORGES, 2010). Sendo assim, as organizações identificadas foram contatadas e obtidas informações a respeito de sua atuação na cadeia da castanha, bem como informações a respeito da produção, comercialização, problemáticas enfrentadas e possíveis soluções por elas vislumbradas. Toda a base de informações foi organizada em planilhas Excel, sendo os dados qualitativos categorizados e analisados de forma descritiva.

A partir dos primeiros contatos e conversas, outros atores locais iam sendo identificados e igualmente contatados, até não haver novas organizações indicadas. Com base nessa metodologia de abordagem, conhecida como bola de neve (VOGT, 1999), foram identificadas 11 organizações atuando na cadeia da castanha em Roraima. Todas elas estavam vinculadas de alguma forma aos povos indígenas Yanomami e Wai Wai.

Enquanto o povo Yanomami se encontra na Terra Indígena Yanomami, os Wai Wai ocupam outras duas Terras Indígenas: TI Wai Wai e TI Trombeta-Mapuera (Figura 1). Essas áreas indígenas somam pouco mais que 14 milhões de hectares ocupados por uma população de mais de 23 mil indígenas; dessa área, 6,7 milhões de hectares estão dentro do território roraimense, correspondendo a praticamente 30\% da área do estado (INSTITUTO SOCIOAMBIENTAL [ISA], 2017). 
Figura 1 - Localização das Terras Indígenas Trombeta-Mapuera, Wai Wai e Yanomami

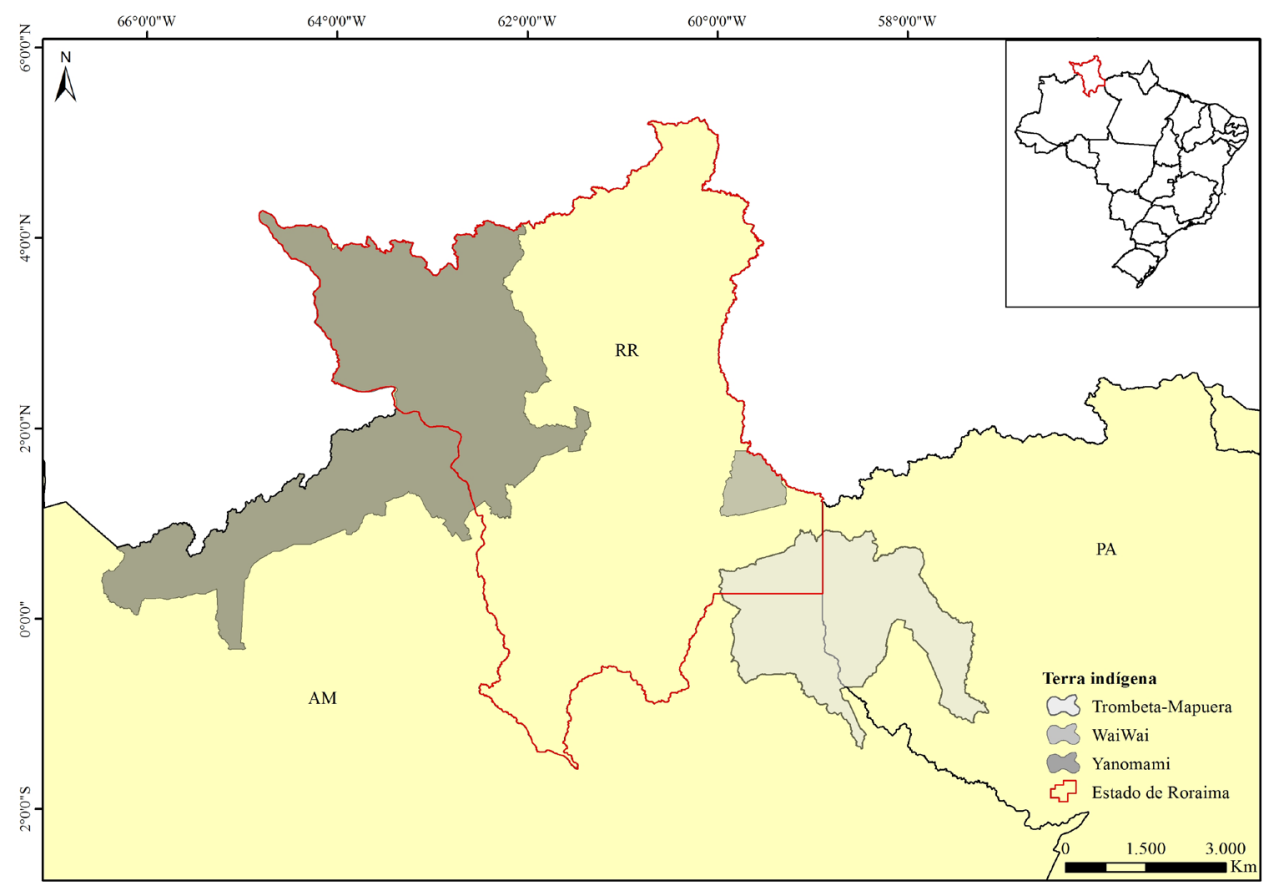

Fonte: Autoria própria.

\section{RESULTADOS}

Diante das dificuldades de comunicação, das 11 organizações identificadas que atuavam na cadeia da castanha, cinco não foram contatadas, sendo uma associação do povo Wai Wai e outra do povo Yanomami, uma empresa pública, uma empresa privada de interesse público e uma representação do governo do estado. Desta forma, seis organizações fizeram parte deste estudo, sendo duas associações de produtores indígenas, duas organizações governamentais federais, uma não governamental e uma empresa privada.

As seis organizações contatadas pertenciam a distintos setores de atuação, porém nenhuma delas havia sido criada para trabalhar diretamente com a castanha. Todas entraram no ramo da castanha há menos de cinco anos deste estudo, aproveitando de sua estrutura, capacidade e recursos já existentes. Enquanto um dos órgãos do Governo Federal tinha a função de fazer cumprir as leis de fiscalização e controle de classificação por tamanho e qualidade das castanhas, as demais organizações atuavam de alguma maneira como apoiadoras na estruturação dessa cadeia produtiva, na etapa de produção e/ou na comercialização do produto (Quadro 1).

Os elos de beneficiamento e transformação da castanha estiveram representados por uma única empresa privada produtora de óleo de castanha, não tendo sido citada nenhuma organização coletiva que atuasse no ramo. 
Quadro 1 - Relação das organizações contatadas e elo de atuação de cada uma na cadeia produtiva da castanha-da-amazônia em Roraima

\begin{tabular}{|l|c|c|c|c|}
\hline \multicolumn{1}{|c|}{ Tipo de organização } & Produção & Comercialização & Transformação & Regulação \\
\hline $\begin{array}{l}\text { Associação } \\
\text { Associação 1 - Wai Wai }\end{array}$ & $X$ & $X$ & & \\
Associação 2 - Yanomami & $X$ & $X$ & & \\
\hline $\begin{array}{l}\text { ONG } \\
\text { ONG 1 }\end{array}$ & $x$ & $x$ & $x$ & \\
\hline $\begin{array}{l}\text { Empresa Privada } \\
\text { Empresa 1 }\end{array}$ & $X$ & $X$ & & \\
\hline $\begin{array}{l}\text { Governo Federal } \\
\text { Governo 1 } \\
\text { Governo 2 }\end{array}$ & & & \\
\hline
\end{tabular}

Fonte: Levantamento de campo.

Ainda que não existisse nenhum grupo de trabalho ou de discussão e nenhuma rede de articulação sobre a cadeia produtiva da castanha-da-amazônia no estado, alguns projetos pontuais vinham dando base à estruturação dessa cadeia. Enquanto um projeto gerenciado por empresa privada de interesse público (não entrevistada) tinha o foco em disseminar as recomendações das boas práticas de manejo junto ao povo Wai Wai, outro projeto coordenado pela ONG 1 dava apoio à coleta e comercialização de castanha pelos Yanomami, tendo ainda subsidiado um intercâmbio com os Wai Wai para que estes compartilhassem com os Yanomami seus conhecimentos a respeito das boas práticas com o produto.

Analisando especificamente como os povos Wai Wai de Roraima estavam organizados em relação à cadeia da castanha (Figura 2), observa-se a atuação de instituições em todos os elos, formando um ciclo completo. Das cinco organizações não contatadas, quatro estavam relacionadas com os Wai Wai e, apesar de não ter sido possível coletar informações mais precisas, foi possível entender como essas se inseriam na cadeia. Todas tinham ações em prol da melhoria da qualidade do produto e investiam na disseminação das boas práticas para a produção da castanha. Apenas uma associação não entrevistada, que correspondia mais a uma entidade de representação do povo Wai Wai, tinha foco de atuação voltado para aumento e organização da produção nos castanhais. 
Figura 2 - Atores institucionais atuantes junto aos povos Wai Wai de Roraima, em diferentes elos/etapas da cadeia produtiva da castanha-da-amazônia. Epup = Empresa privada de interesse público; N/E = não entrevistada

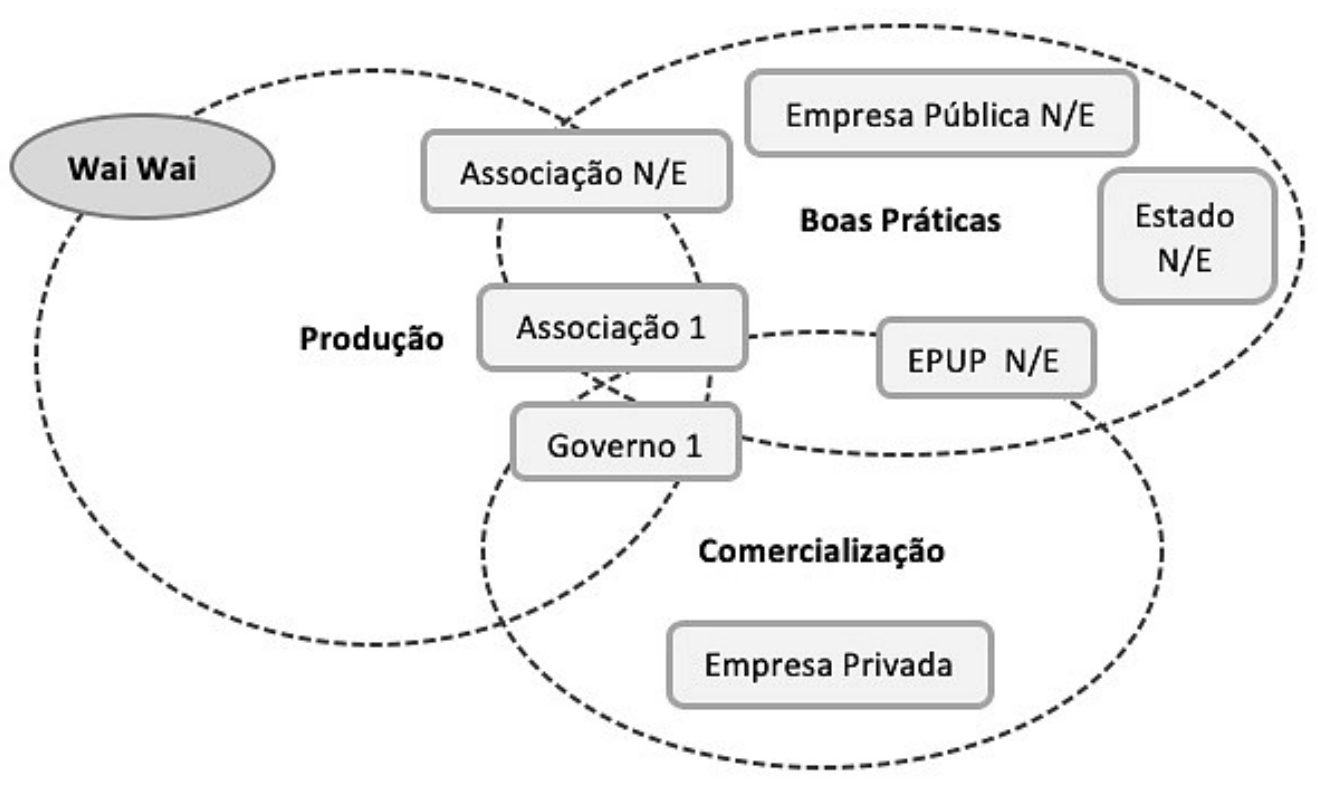

Fonte: Autoria própria.

Diante da articulação feita com outras organizações apoiadoras, nos últimos anos os extrativistas Wai Wai começaram a se envolver mais nas temáticas relacionadas à produção e melhoria da qualidade da castanha (Figura 2), buscando uma maior organização e melhor planejamento das etapas de produção. Também foram realizados mapeamento e manejo dos castanhais, o que proporcionou aumento na produção das castanheiras. Ainda, como a aplicação das boas práticas surtiu efeito e foi notável a melhora na qualidade das castanhas produzidas, com consequente aumento no preço de venda, os Wai Wai passaram a se interessar mais pelas boas práticas e a se envolverem nas questões da comercialização da castanha. No entanto, embora o apoio dado aos Wai Wai, por parte das organizações envolvidas, tenha proporcionado a venda coletiva da castanha e, consequentemente, uma menor dependência dos atravessadores, esse elo da comercialização ainda parece frágil, uma vez que o único canal seguro de venda estava direcionado a uma única empresa.

No caso dos Yanomami, em que se observou um menor número de organizações apoiadoras, praticamente todo o apoio estava focado em aumentar a produção, com algumas iniciativas de disseminação das boas práticas e melhoria da qualidade do produto (Figura 3). A comercialização de castanha pelos Yanomami é recente, tendo começado em 2010, quando foi feito um mapeamento dos castanhais coletados, que registrou aproximadamente 300 castanheiras (o que representa uma porção muito pequena da $\mathrm{TI}$ ), e quando o povo indígena Ye'kuana orientou os Yanomami a construírem suas próprias canoas, possibilitando o escoamento da produção. Como era uma atividade recente para os Yanomami, na época deste estudo, havia certa dependência da ONG 1 e do Governo 1 para conseguir comercializar sua produção a melhores preços, indicando fragilidade na comercialização, sendo, portanto, no que deveriam ser dedicados maiores esforços.

De qualquer forma, os incentivos à coleta e comercialização da castanha Yanomami proporcionados pela articulação entre as organizações apoiadoras melhorou a logística de coleta, 
a organização para a venda e a qualidade da castanha. Assim, permitiu um aumento na produção e no preço pago ao produto. Os indígenas passaram a entender melhor a importância do seu próprio trabalho com a castanha, dando mais valor à atividade. Uma vez que a coleta de castanha proporciona maior união das famílias e aumenta a sua segurança alimentar, além de a atividade incentivar a permanência do seu povo na floresta, outra vantagem citada foi que as famílias envolvidas com a produção de castanha passaram a se preocupar mais com a manutenção dos castanhais e, consequentemente, da floresta, envolvendo-se menos com os garimpeiros e fazendeiros da região.

Figura 3 - Atores institucionais atuantes junto aos povos Yanomami de Roraima, em diferentes elos/etapas da cadeia produtiva da castanha-da-amazônia

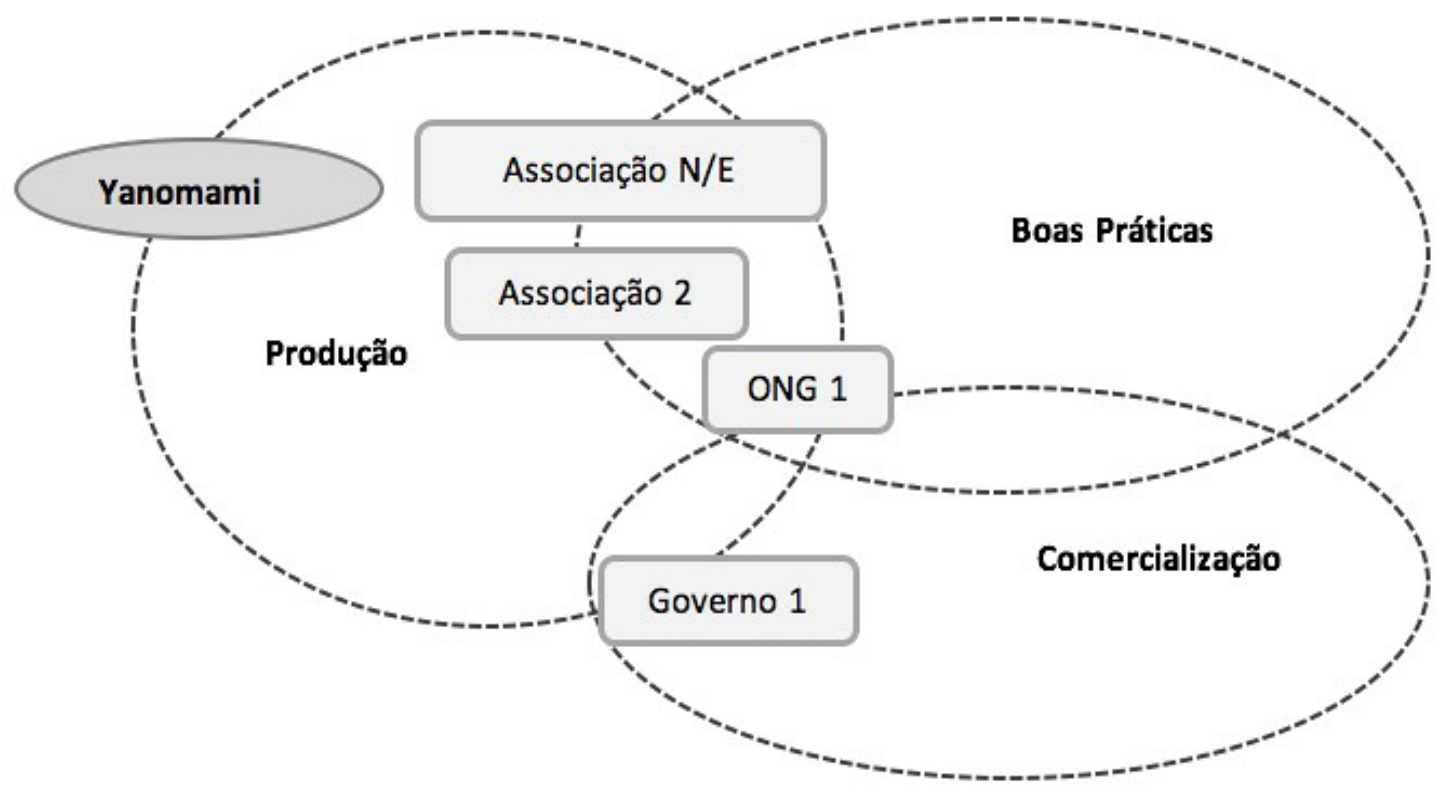

Fonte: Autoria própria.

\section{1 Produção de castanha nas Terras Indígenas}

Em 2014, aproximadamente 800 indígenas estavam envolvidos na produção e se beneficiavam com a comercialização de castanha nas Terras Indígenas Wai Wai, TrombetaMapuera e Yanomami. A castanha e a farinha eram, nessa ordem, os principais produtos geradores de renda para mais de 120 famílias. Alguns membros dessas famílias também recebiam recursos de programas de assistência social dos governos federal (Bolsa Família, aposentadoria, auxíliomaternidade) e estadual (crédito social), e outros ainda eram funcionários públicos (professores, agentes de saúde e agentes sanitários).

A importância da castanha na vida dessas famílias é tamanha, que nos povos Wai Wai, durante a época da coleta, o calendário escolar é adaptado de forma que toda a família possa se deslocar para os castanhais. Para o povo Yanomami, embora a comercialização fosse um negócio recente (primeira venda coletiva em 2010), a coleta já era uma atividade tradicional e familiar, com a ressalva de que dificilmente a mulher participava da etapa de coleta.

Dependendo da comunidade indígena, os meses de início e término da safra da castanha variam um pouco, mas, de modo geral, a duração da safra foi de três a quatro meses - entre 
maio e setembro - sendo que, de junho a agosto, a coleta era mais intensa. Pensando em oportunidades de mercado, a época pode ser vantajosa para os produtores de Roraima, uma vez que a produção em todos os outros estados, ou seja, a maior parte da produção brasileira, ocorre no inverno amazônico, entre os meses de novembro e maio (WADT; KAINER, 2009). Isso significa dizer que as castanhas de Roraima são produzidas na época da entressafra nacional, quando o mercado tende a demandar o produto in natura e o preço pago costuma ser maior.

Em se tratando do acesso aos castanhais, é importante ressaltar que esses costumavam estar em áreas distantes das aldeias, geralmente acessados após um dia inteiro de deslocamento para chegar até a área, demandando maior tempo e dedicação dos coletores e suas famílias. Mesmo sendo áreas extensas de floresta, não foram relatados conflitos em relação ao uso dos castanhais. No caso dos Wai Wai, o fato de os coletores conhecerem e respeitarem os limites dos castanhais uns dos outros favorece a boa convivência entre as famílias. Além disso, esse comportamento tem sido trabalhado durante as assembleias da associação, em que se discute sobre a definição dos limites e das regras de uso dos castanhais. Entre os Yanomami, não foi relatada discussão de limites e regras de uso dos castanhais em assembleias, não havendo também relatos de conflitos. Uma das explicações prováveis é o fato de as áreas de coleta serem muito extensas e a quantidade de coletores ainda pequena, embora essa situação possa mudar futuramente.

Nas terras Wai Wai, foi relatado não haver pressão externa nas áreas de coleta, uma vez que havia uma forte fiscalização. Ao contrário, a terra Yanomami vem sendo intensamente ameaçada pela grilagem de terras e pela exploração de madeira, o que gera grande pressão sobre as áreas de terra firme, lugar de ocorrência dos castanhais (PRANCE, 1990). Ações de proteção vêm sendo desenvolvidas em articulação com diferentes frentes para tentar resolver esses conflitos.

Informações obtidas neste trabalho relatam que a história da TI Yanomami teve episódios que resultaram em muitas mortes e na desunião do seu povo indígena, o que trouxe consequências relacionadas à baixa organização social. Preocupados com isso, os indígenas buscaram se unir e formar uma associação que pudesse apoiá-los na luta por seu território e por seus direitos. Como o cunho dessa entidade era principalmente político, poucos indígenas entendiam a importância de participarem da associação; no entanto, com o maior envolvimento na produção da castanha, esse cenário começou a mudar. Um dos principais interesses em se investir na cadeia produtiva da castanha foi pelo fato de essa atividade proporcionar um maior contato com a floresta e melhorar a qualidade de vida das pessoas, já que a oferta de alimento aumenta, proporcionando certa segurança alimentar durante os meses da safra.

Foi registrada uma produção de pelo menos 164 toneladas de castanha in natura que foram comercializadas coletivamente pelos povos Wai Wai e Yanomami durante a safra de 2013. A maior parte dessa produção (160 t = 4 mil sacas) foi oriunda de territórios Wai Wai, uma vez que a comercialização coletiva é algo novo para os Yanomami. No entanto é difícil estimar a produção total de castanha nessas TIs, uma vez que não há registros e as formas e os meios de comercialização são diversos. Uma parte das castanhas é consumida pela família ou intercambiada entre parentes indígenas; outra parte é vendida diretamente a atravessadores, havendo ainda casos, como o dos Yanomami, em que parte da produção foi escoada diretamente ao estado do Amazonas pela bacia do rio Branco e vendida a uma cooperativa de castanha no rio Unini, na bacia do rio Negro. Existem ainda as castanhas que não são coletadas e ficam na floresta, por não se conhecer a localização das árvores, por falta de coletores, pela dificuldade logística ou por qualquer outra razão. 
Entre todos os atores que participaram desta pesquisa, foi consenso que, de fato, a produção de castanha estava muito aquém do potencial produtivo dessas três TIs. Por exemplo, na Associação Wai Wai, a produção chega a ser de 300 t ( \pm 7.000 sacas) por safra, sendo que, em 2010, apenas da TI Wai Wai foram comercializadas aproximadamente $231 \mathrm{t}$ de castanha in natura - mesmo com o número de famílias que trabalharam na coleta sendo relativamente baixo, de menos de 30\% (TONINI et al., 2014). Entretanto, quando se comparam as informações de produção obtidas na coleta dos dados (relatados acima), com os dados oficiais do governo (Tabela 1), tem-se uma ideia do quanto as estatísticas oficiais são subestimadas.

Tabela 1 - Produção e preço da castanha-da-amazônia em Roraima, segundo os dados oficiais do IBGE (2019)

\begin{tabular}{lccccccccc}
\hline Ano & $\mathbf{2 0 1 0}$ & $\mathbf{2 0 1 1}$ & $\mathbf{2 0 1 2}$ & $\mathbf{2 0 1 3}$ & $\mathbf{2 0 1 4}$ & $\mathbf{2 0 1 5}$ & $\mathbf{2 0 1 6}$ & $\mathbf{2 0 1 7}$ & $\mathbf{2 0 1 8}$ \\
\hline Produção (t) & 106 & 105 & 112 & 171 & 166 & 155 & 161 & 322 & 2.230 \\
Valor total (mil R\$) & 68,00 & 68,00 & 79,00 & 420,00 & 455,00 & 489,00 & 563,00 & 966,00 & $5.899,00$ \\
Valor unit. (R\$/t) & 641,51 & 647,62 & 705,36 & 2456,14 & $2.740,96$ & $3.154,84$ & $3.496,89$ & $3.000,00$ & $2.645,29$ \\
\hline
\end{tabular}

Fonte: Autoria própria.

Em se tratando de preços, especialmente nos últimos anos, com os investimentos das organizações apoiadoras em melhorar a produção e a venda coletiva da castanha, o preço pago ao produtor tem aumentado (Tabela 1 ) e tem sido um grande atrativo às demais famílias indígenas. Antes de 2013, o preço médio da castanha in natura era de $\mathrm{R} \$ 35,00$ a saca $^{5}$, valor este que, em 2013, variou de $\mathrm{R} \$ 70,00$ a $\mathrm{R} \$ 120,00$, sendo que alguns atravessadores chegaram a pagar $\mathrm{R} \$ 190,00$. Apesar dessa valorização, quando se compara com os valores de $\mathrm{R} \$ 45,00$ / saca estipulados na Pauta de Valores do Preço Mínimo do Estado (RORAIMA, 2015), fica clara a necessidade de monitoramento do mercado e atualização dos preços praticados por essa política governamental de incentivo à produção.

De qualquer maneira, a produção de castanha sempre foi de suma importância para as famílias indígenas coletoras, pois, além de contribuir para a alimentação, gera uma renda representativa na economia familiar. Tomando como referência a produção e os preços de 2013, estima-se que os Yanomami receberam algo em torno de $\mathrm{R} \$ 10$ mil com a venda de $4 \mathrm{t}$ de castanha, enquanto os Wai Wai, aproximadamente $\mathrm{R} \$ 400$ mil, oriundos da comercialização de 160 t. Ambas as organizações receberam o mesmo valor de $\mathrm{R} \$ 2,50 / \mathrm{kg}$ de castanha in natura. Sendo assim, com base nas 120 famílias envolvidas na venda coletiva, estima-se que a coleta de castanha tenha gerado, para os dois povos em questão, uma renda média de $\mathrm{R} \$ 3,4$ mil por família. Ainda, em se tratando da importância da comercialização da castanha, vale a pena reforçar a valorização que esse produto tem apresentado nos últimos anos (Tabela 1).

\subsection{Fluxos de comercialização da castanha}

O caminho percorrido pelas castanhas, desde a floresta até o consumidor final, pode passar por muitas etapas. No contexto deste estudo, as castanhas foram coletadas e transportadas pelos indígenas que percorriam as trilhas de coleta dentro dos castanhais, geralmente a pé. Os

\footnotetext{
${ }^{5}$ A principal unidade de medida de comercialização de castanha in natura em Roraima é a saca, que corresponde a quatro latas de 20 litros, ou seja, 80 litros de castanha.
} 
indígenas utilizam, tanto para ter acesso aos castanhais como para escoar a produção, meios de transporte fluvial (barco, lancha, canoas com motor de popa) e terrestre para levar as castanhas até as aldeias, onde cada família armazena à sua maneira.

A partir do momento em que a castanha chega às aldeias, existem diversas possibilidades de comercialização (Figura 4). No período pesquisado, uma grande parte da castanha foi vendida para atravessadores dos mais diversos tipos, que por sua vez revendiam a castanha in natura para mais de um elo até chegar às empresas beneficiadoras situadas no Amazonas, Acre e até mesmo Pará. Entretanto as ações de entidades apoiadoras, nos últimos anos, resultaram em uma quebra da força desses compradores junto aos povos Wai Wai e Yanomami. Em 2013, por exemplo, uma parte dos Yanomami teve apoio para fretar um caminhão e transportar a castanha até a feira de Boa Vista, onde foi vendida em grandes quantidades e a melhores preços. Já mais ao sul da TI, uma parte desses indígenas também começou a vender castanha, direta ou indiretamente, a uma cooperativa recentemente formada no rio Unini, Amazonas. Os Wai Wai, por meio de sua associação, também conseguiram se articular e garantir a venda de grande parte da produção de castanha a uma empresa privada local situada no município de Rorainópolis, RR.

Figura 4 - Fluxo comercial da castanha originária dos povos indígenas Wai Wai (TI Wai Wai e TI Trombeta-Mapuera) e Yanomami (TI Yanomami) do estado de Roraima, comercializada em 2013, com indicações dos tipos de produtos comercializados

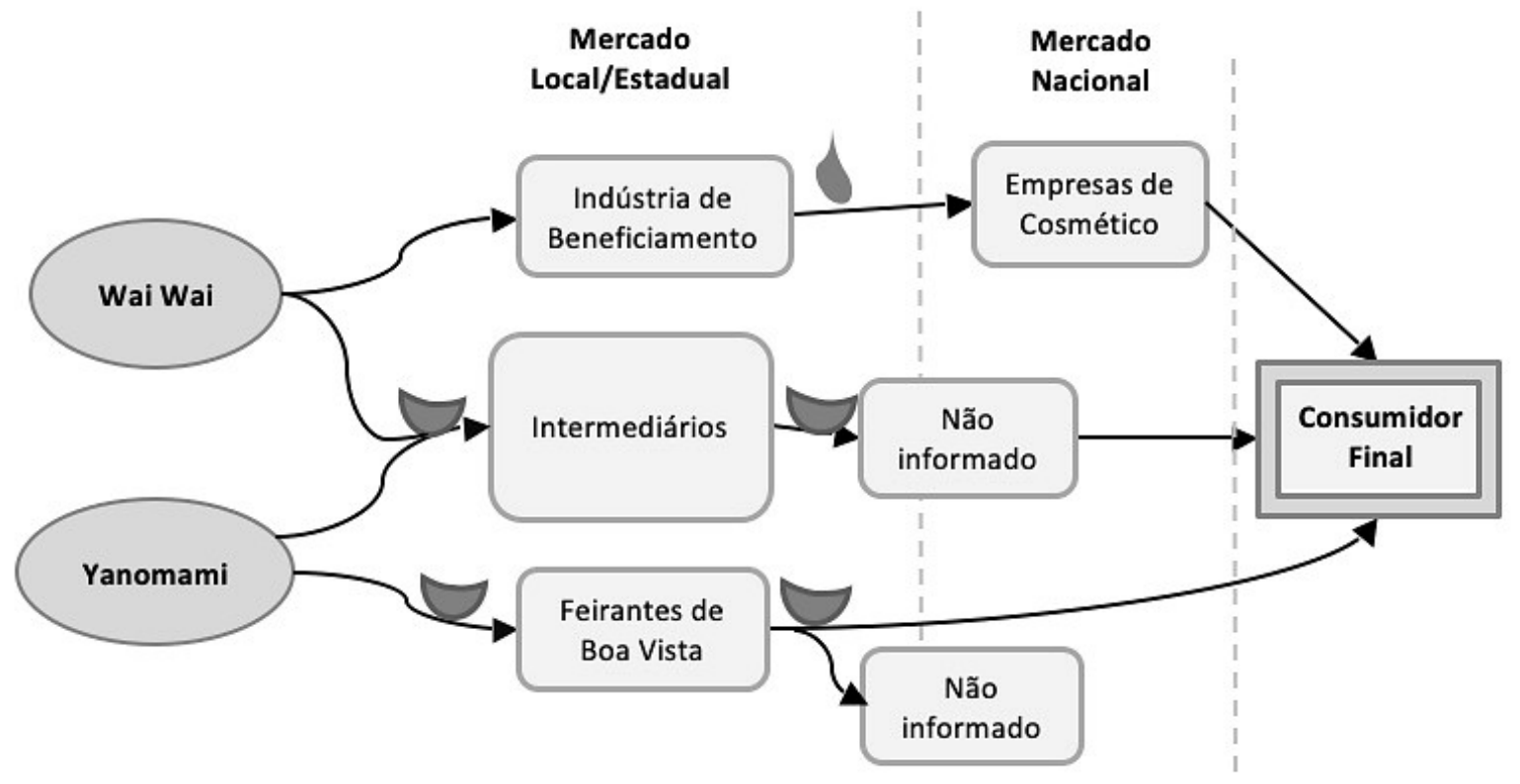

Legenda: $\Psi$ = castanha in natura e $\circlearrowleft$ óleo de castanha.

Fonte: Autoria própria.

Até 2013, praticamente toda a comercialização de castanha em Roraima era feita com o produto in natura. O único processo de beneficiamento da castanha no estado era realizado por essa empresa entrevistada que, além de beneficiar, transformava a castanha por meio da prensagem a frio, tendo como principal produto o óleo de castanha. Devido ao seu potencial cosmético e medicinal, a proposta foi de vender o óleo a empresas de fora do estado que atuassem nesse ramo. No entanto, por empecilhos legais, apenas uma pequena parte do óleo chegou a 
ser vendida a uma empresa de cosméticos na região sudeste do Brasil, sendo que a maior parte desse produto ficou estocada até a época deste estudo.

Os custos com essa logística de coleta e escoamento da castanha normalmente eram arcados pelo próprio coletor, muitas vezes subsidiado por projetos geridos pelas organizações de apoio. Os Yanomami, por exemplo, contavam com o apoio de sua Associação e da ONG 1, que emprestavam seus veículos e ainda financiavam os gastos com deslocamento a partir de recursos oriundos da Política Nacional de Gestão Territorial e Ambiental de Terras Indígenas (PNGATI). Em algumas situações, dependendo da negociação feita entre as partes, esses custos ainda eram compartilhados com os próprios compradores da castanha, como foi o caso dos Wai Wai, que, em 2013, fretaram um caminhão que levava a castanha das aldeias até a margem de um rio e, dali, a empresa se responsabilizava pelos custos dos transportes fluvial e terrestre necessários para que a castanha fosse transportada até a usina da empresa.

\subsection{Estratégias de comercialização}

Até 2013, toda a castanha comercializada pelos Wai Wai era vendida a atravessadores locais; porém, nesse mesmo ano, a associação fechou um contrato de venda direta com a única empresa de castanha do estado, para a qual vendeu parte de sua produção. Trata-se de uma empresa privada produtora de óleo de castanha certificado, que estava iniciando suas atividades em Roraima. Um dos benefícios dessa venda foi que, enquanto os custos de escoamento da produção eram exclusivamente do coletor, com a empresa, passaram a ser divididos entre as partes. Até o momento deste estudo, não havia registros de iniciativa coletiva para beneficiamento ou transformação da castanha.

A relação comercial com a empresa privada de Roraima começou devido à necessidade de garantia de compra e de venda entre os envolvidos. Por um lado, os indígenas estavam passando por um processo de melhoria da qualidade da castanha produzida, melhoria esta iniciada com capacitação dos extrativistas em boas práticas de manejo, incentivo e apoio à coleta e articulação para a venda da castanha a preços melhores. Por outro lado, a empresa estava iniciando um novo negócio e precisava ter a aquisição da matéria-prima principal garantida, condição essencial em se tratando de castanha - um produto com grandes oscilações de produção (KAINER; WADT; STAUDHAMMER, 2007; ZUIDEMA; BOOT, 2002) e de preço (SANTANA et al., 2017). Ainda, a compra é historicamente comandada por atravessadores (TONINI; BORGES, 2010; TONIN; LOPES; ARAUJO, 2014), que mantêm com os produtores relações de dívida e dependência.

Embora seja evidente a necessidade do comprometimento de ambos os lados (comprador e vendedor), a realidade costuma ser bem diferente. Normalmente, as relações do negócio com castanha são informais e de alto risco, uma vez que não há garantias além da própria palavra dos acordantes. Nessa negociação com a empresa de óleos, os Wai Wai providenciaram a assinatura de um contrato de compra e venda em que a quantidade, o preço e o prazo de entrega ficaram bem definidos. Essa evolução na forma de comercialização de castanha deu maior garantia aos indígenas e à empresa, que fez questão de frisar a satisfação com o comprometimento dos indígenas com a entrega da castanha. 


\subsection{Boas Práticas}

A qualidade da castanha que chega ao consumidor final depende da aplicação de boas práticas durante a coleta, especialmente secagem, seleção, armazenamento e comercialização. Há uma série de recomendações de boas práticas para o manejo ou produção de castanha (APIZ, 2010; BRASIL, 2014; WADT et al., 2005), as quais vêm sendo disseminadas por meio de cursos e capacitações feitas com os mais diferentes elos da cadeia de produção da castanha em toda a região amazônica.

No contexto deste estudo, até 2013, apenas os Wai Wai haviam recebido cursos de boas práticas. Foram três cursos organizados pela própria associação indígena, com o apoio de uma empresa pública, outra privada de interesse público e um órgão do governo estadual. Um dos resultados desses processos de formação foi a construção de um paiol comunitário na comunidade de Jatapuzinho (TI Trombeta-Mapuera) e a aplicação das boas práticas por muitos dos produtores indígenas, o que tem melhorado a qualidade da castanha por eles produzida e, por sua vez, facilitado sua comercialização, uma vez que existe uma demanda de mercado por castanhas de boa qualidade.

Embora muitos coletores de castanha tenham recebido informações sobre os cuidados que se deve ter ao longo da produção e comercialização da castanha, nem sempre as recomendações são aplicadas e as explicações relatadas foram das mais diversas, como o fato de haver pouco incentivo financeiro para a aplicação dessas práticas. Por outro lado, uma ação mencionada pelos indígenas Wai Wai que aplicaram as boas práticas foi o fato de terem recebido acompanhamento técnico durante 10 a 15 dias da coleta.

Para os Yanomami, não houve nenhuma capacitação sobre boas práticas de manejo da castanha. Apenas em 2013, houve um intercâmbio de experiências com os indígenas Wai Wai, organizado e patrocinado por organizações parceiras desse povo. Pensou-se em construir um galpão comunitário, mas a ideia ainda precisava de amadurecimento entre os próprios indígenas. Os Yanomami ainda não comercializavam grandes quantidades de castanha e os atravessadores não eram exigentes quanto à qualidade do produto, pois toda a produção de castanha Yanomami era vendida sem dificuldades, mesmo que sem boas práticas. Isso acabou sendo um empecilho ao interesse dos indígenas pelas boas práticas de manejo.

\subsection{Acesso a políticas públicas}

Algumas políticas públicas foram importantes na estruturação da cadeia produtiva da castanha no Brasil, especialmente no período de 2003 a 2014. Muitas dessas políticas estavam vinculadas ao Plano Nacional de Promoção de Cadeias de Produtos da Sociobiodiversidade (PNPPS) $^{6}$. No caso das organizações envolvidas neste estudo, apenas o povo Wai Wai acessou algumas dessas políticas. Por meio de projetos paralelos liderados pelas organizações parceiras,

\footnotetext{
${ }^{6}$ Criado pela Portaria Interministerial MDA/MDS/MMA n. 239, de 21/07/09. Suas ações estão voltadas para os seguintes eixos: 1) promoção e apoio à produção e ao extrativismo sustentável; 2) estruturação e fortalecimento dos processos industriais; 3) estruturação e fortalecimento de mercados para os produtos da sociobiodiversidade; 4) fortalecimento da organização social e produtiva; 5) ações complementares para fortalecimento das cadeias de produtos da sociobiodiversidade; 6) ações complementares para a valoração dos serviços da sociobiodiversidade (http://www.mma.gov.br/desenvolvimento-rural/sociobiodiversidade). Acesso em: 24/10/2018.
} 
o Programa Carteira Indígena ${ }^{7}$ estava sendo utilizado para apoiar especialmente questões relacionadas à melhoria do transporte e da qualidade da castanha, enquanto o Programa de Aquisição de Alimentos (PAA) ${ }^{8}$ chegou a apoiar a comercialização por meio da modalidade Formação de Estoques de castanha e sua destinação ao mercado institucional, durante os anos de 2011 e 2012. Nesse biênio, o PAA destinou R\$ 591,3 mil à associação Wai Wai entrevistada para a compra de $890 \mathrm{~kg}$ de castanha in natura (preço médio $=\mathrm{R} \$ 0,80 / \mathrm{kg}$ ). Outra associação Wai Wai também vendeu, nesses mesmos dois anos, 302,7 kg de castanha in natura para o PAA a um preço médio de $\mathrm{R} \$ 0,60 / \mathrm{kg}$, o que lhe gerou uma receita de $\mathrm{R} \$ 181,6$ mil.

Embora o PAA possibilitasse certa garantia de venda e certo reconhecimento para os Wai Wai como um dos poucos povos indígenas a acessar políticas públicas de estruturação das cadeias produtivas da sociobiodiversidade, nenhuma dessas associações continuaram acessando o programa. Neste estudo, não se identificaram quais foram os motivos pelos quais as organizações Wai Wai deixaram de se beneficiar do PAA. De acordo com a Associação Yanomami, uma das razões de não acessarem o PAA, no período do estudo, foi o fato de o programa operar com preços muito baixos em relação aos preços do mercado local.

\subsection{Principais gargalos da cadeia produtiva}

Os principais gargalos identificados na cadeia produtiva da castanha em Roraima, em especial para os povos indígenas Wai Wai e Yanomami, foram a logística de escoamento e a falta de infraestrutura para o beneficiamento da castanha no estado.

Sendo a castanha um produto altamente nutritivo e mediante os riscos de contaminação por aflatoxinas ${ }^{9}$, fazem-se necessários investimentos para a sensibilização dos coletores sobre boas práticas de manejo, bem como em infraestrutura local de secagem e armazenamento e, até mesmo, em unidades de beneficiamento local da castanha in natura. Isso possibilitaria aumentar o rendimento, diversificar a produção e acessar melhores preços e novos mercados com uma castanha de melhor qualidade.

Por outro lado, o sucesso de um negócio depende necessariamente da logística de escoamento do produto. No caso da castanha oriunda dessas Terras Indígenas, o cerne da problemática do escoamento está na dificuldade de acesso aos castanhais e nas péssimas condições das estradas utilizadas. Uma das soluções apontadas foi o planejamento prévio da coleta, focando no uso mais eficiente do transporte. No entanto, como a melhoria das estradas de escoamento pode trazer consequências negativas aos povos e territórios indígenas (com

\footnotetext{
${ }^{7}$ Carteira de Projetos Fome Zero e Desenvolvimento Sustentável em Comunidades Indígenas (Carteira Indígena) - ação do governo federal, resultado de parceria entre o Ministério do Meio Ambiente (MMA), por meio da sua Secretaria de Extrativismo e Desenvolvimento Rural Sustentável (SEDR), e o Ministério do Desenvolvimento Social e Combate à Fome (MDS), por meio da sua Secretaria Nacional de Segurança Alimentar e Nutricional (Sesan), cujo objetivo era contribuir para a gestão ambiental das terras indígenas e a segurança alimentar e nutricional das comunidades indígenas, em todo o território nacional (http://www.mma.gov.br/informma/itemlist/category/38carteira-indigena). Acesso em: 24/10/2018.

${ }^{8}$ Criado em 2003, consiste em ação do Governo Federal para colaborar com o enfrentamento da fome e da pobreza no Brasil e para o fortalecimento da agricultura familiar.

${ }^{9}$ A aflatoxina é uma micotoxina produzida por espécies de fungos do gênero Aspergillus. É um dos principais tipos de micotoxinas, presente em diversos alimentos, sendo considerada uma contaminação que representa risco para a saúde de humanos e animais domésticos. Aflatoxinas são descritas como tendo atividade imunossupressora, mutagênica, teratogênica e hepatocarcinogênica. A aflatoxina B1 foi classificada como carcinógeno tipo 1, sendo considerada um dos principais fatores de risco para carcinoma hepatocelular (HCC).
} 
destaque para a estrada que atravessa a TI Trombeta-Mapuera e a que conecta com a rodovia BR-210), ainda é preciso promover maiores diálogos, principalmente com os jovens, para se ter um consenso e uma decisão coletiva a respeito da real necessidade de se melhorarem as estradas.

As dificuldades em acessar diretamente os mercados consumidores têm sido outra preocupação das associações. Para ampliar o mercado, é preciso empoderar os produtores nas negociações comerciais, especialmente no que diz respeito à venda coletiva de castanha. A formação de uma cooperativa que possa beneficiar a castanha in natura, diversificar e comercializar sua produção também pode ajudar a acessar diferentes tipos de mercado consumidor. Ainda, a agregação de valor por meio da certificação da produção de castanha via selo de reconhecimento da identidade de origem étnica é uma alternativa que valeria a pena ser considerada. A Fundação Nacional do Índio (Funai) havia lançado o selo Indígenas do Brasil em 2014. Entretanto, após os cortes nos orçamentos da instituição desde 2016, as ações para implementação do selo foram descontinuadas.

Outra problemática está relacionada à flutuação nos preços de mercado da castanha, especialmente para o elo do produtor. A negociação de contratos de compra e venda pode ser uma forma de garantia da comercialização, embora outras estratégias possam ser elaboradas.

A frágil organização interna das entidades de representação social dos produtores e comportamentos naturais do ser humano, como o individualismo, foram considerados fatores que dificultavam as ações coletivas em prol da produção e comercialização de castanha articuladas em rede. Muitas são as possibilidades de lidar com essas questões dependendo de cada contexto, mas o que se pode afirmar é que, de modo geral, os problemas mencionados não foram muito diferentes dos que ocorrem nas demais regiões brasileiras produtoras de castanha (GARCÉS et al., 2015; BROSE; 2016). Nesse contexto, geralmente é sugerida como solução prioritária a busca pelo estabelecimento de parcerias, a fim de que haja um maior número de pessoas se mobilizando e ajudando na formação e estruturação de um encadeamento de atores e processos. Políticas de crédito e de financiamento, inclusive financiamento em rede, devem também ser consideradas, pois podem ser uma boa maneira de formar capital de giro e resolver outro problema comumente enfrentado pelas organizações de base.

Para o representante do organismo de regulação, um dos principais problemas da cadeia produtiva em Roraima estava relacionado à impossibilidade de analisar a qualidade da castanha no estado. O fato de os laboratórios estarem situados em outras regiões do país inviabilizaria a análise e, consequentemente, a comercialização do produto para o exterior.

Do ponto de vista da empresa de óleo de castanha, as regras impostas pelo Conselho de Gestão do Patrimônio Genético (CGEN) foram os únicos empecilhos para a comercialização do produto beneficiado. Como a produção de 2013 da empresa dependeu basicamente de castanhas negociadas com uma associação indígena, as regras de acesso ao patrimônio genético inviabilizaram a comercialização do óleo produzido, sendo que a empresa foi obrigada a estocar toda a sua produção. Naquela época, os trâmites, processos e regras não estavam claros para se conduzir uma parceria comercial entre uma empresa e uma organização indígena. Essa problemática gerou uma desestruturação e desmotivação da rede de relações iniciada em torno da produção e comercialização de castanha, culminando no fechamento do negócio com a castanha. 


\section{CONSIDERAÇÕES FINAIS}

Apesar de Roraima ser o estado brasileiro com menor produção registrada de castanha-da-amazônia até 2017, a atividade de coleta e comercialização representa uma importante fonte de renda para as famílias e organizações indígenas locais.

Duas organizações indígenas (Wai Wai e Yanomami) se destacaram no estado como produtoras de castanha-da-amazônia. Não obstante o fato de ambas terem protagonizado parte da estruturação da cadeia produtiva no estado, receberam apoios diferenciados, resultando em diferentes estratégias de melhoria da qualidade e inserção nos mercados. Apesar de este estudo ter sido realizado em 2014 e 2015, os dados oficiais de produção de castanha do estado (IBGE, 2019), em 2018, demonstram que os investimentos em capacitação, infraestrutura e apoio à comercialização renderam bons frutos. Em 2018, o estado de Roraima passou de último colocado, no ranking de produção nacional, para o terceiro lugar.

A despeito de não ter sido possível contatar todos os atores institucionais identificados, conseguiram-se informações relevantes a respeito da atuação desses na cadeia produtiva da castanha no estado, o que permitiu um entendimento sobre seus principais gargalos, possibilitando vislumbrar algumas soluções viáveis no médio e longo prazo, sendo elas: capacitação e acompanhamento técnico dos extrativistas em boas práticas de manejo e monitoramento da produção; infraestrutura local nas áreas de coleta para aplicação das boas práticas de coleta; gestão comunitária para organização da produção e para acessar novos mercados; fortalecimento de uma rede de parcerias para estruturação da cadeia produtiva da castanha; infraestrutura no estado para o beneficiamento da castanha.

\section{REFERÊNCIAS}

ASSOCIAÇÃO DO POVO INDÍGENA ZORÓ. Boas práticas de coleta, armazenamento e comercialização da castanha-do-Brasil: capacitação e intercâmbio de experiências entre os povos da Amazônia mato-grossense com manejo de produtos florestais não-madeireiros. Cuiabá: Defanti, 2010.

BRASIL. Ministério do Desenvolvimento Agrário. Secretaria de Desenvolvimento Territorial. Territórios da cidadania: sul de Roraima - Perfil Territorial. Brasília, DF, 2015. 6 p. Disponível em: http://sit.mda.gov. br/download/caderno/caderno_territorial_091_Sul\%20de\%20Roraima\%20-\%20RR.pdf. Acesso em: 13 dez. 2018.

BRASIL. Ministério da Agricultura, Pecuária e Abastecimento. Secretaria de Desenvolvimento Agropecuário e Cooperativismo. Caderno de boas práticas para o extrativismo sustentável orgânico da castanha-dobrasil. Brasília, DF, 2014. 41 p. (Série Boas práticas de manejo para o extrativismo sustentável orgânico). Disponível em: http://www.agricultura.gov.br/assuntos/sustentabilidade/organicos/arquivos-publicacoesorganicos/castanha-do-brasil.pdf. Acesso em: 12 jan. 2019.

BROSE, M. E. Cadeias produtivas sustentáveis no desenvolvimento territorial: a castanha na Bolívia e no Acre, Brasil. Interações, Campo Grande, MS, v. 17, n. 1, p. 77-86, jan./mar. 2016.

GARCÉS, C. L. L.; PÉREZ, S. E. G.; SILVA, J. A.; ARAÚJO, M. O.; COELHO-FERREIRA, M. Objetos indígenas para o mercado: produção, intercâmbio, comércio e suas transformações. Experiências Ka'apor e MebêngôkreKayapó. Boletim do Museu Paraense Emílio Goeldi. Ciências Humanas, Belém, v. 10, n. 3, p. 699-80, set./ dez. 2015.

INSTITUTO BRASILEIRO DE GEOGRAFIA E ESTATÍSTICA (Brasil). Produção da extração vegetal e da silvicultura. Rio de Janeiro: IBGE, 2019. Disponível em: https://sidra.ibge.gov.br/tabela/289. Acesso em: 30 out. 2019. 
INSTITUTO NACIONAL DE PESQUISAS ESPACIAIS (Brasil).. Programa de Cálculo do Desflorestamento da Amazônia - PRODES. São José dos Campos: INPE, 2015. Disponível em: http://www.dpi.inpe.br/ prodesdigital/prodesmunicipal.php. Acesso em: 17 fev. 2018.

INSTITUTO SOCIOAMBIENTAL (Brasil). Terras indígenas no Brasil. Brasília: ISA, 2017. Disponível em: https://terrasindigenas.org.br. Acesso em: 18 dez. 2017.

KAINER, K. A.; WADT, L. H. O.; STAUDHAMMER, C. L. Explaining variation in Brazil nut fruit production. Forest Ecology and Management, Amsterdam, v. 250, n. 3, p. 244-55, out. 2007.

PRANCE, G. T. Bertholletia. In: MORI, S. A.; PRANCE, G. T. (Ed.). Lecythidaceae-Part II: the zygomorphicflowered new world genera (Couroupita, corythophora, Bertholletia, Couratari, Eschweilera, \& Lecythis). New York: New York Botanical Garden, 1990. p. 114-8.

RORAIMA (Estado). Portaria GAB/SEFAZ n. 835, de 3 de novembro de 2015. Altera o Anexo I da SEFAZ/ GAB/PORTARIA, de 14 de março de 2012, que dispõe sobre a Pauta de Valores de Preços Mínimos. Diário Oficial [do] Estado de Roraima, Boa Vista, RR, 3 nov. 2015. Disponível em: https://www.legisweb.com.br/ legislacao/?id=305735. Acesso em: 8 nov. 2018.

SANTANA, A. C.; SANTANA, Á. L.; SANTANA, Á. L.; MARTINS, C. M. Valoração e sustentabilidade da castanhado-brasil na Amazônia. Revista de Ciências Agrárias, Belém., v. 60, n. 1, p. 77-89, jan./mar. 2017.

TONINI, H.; LOPES, C. E. V.; KAMINSKI, P. E.; COSTA, P. Perfil do extrativismo e características da cadeia produtiva da castanha-do-brasil em projetos de reforma agrária do sul do Estado de Roraima. Boa Vista: Embrapa Roraima, 2006.

TONINI, H.; BORGES, R. A. O extrativismo da castanha-do-brasil na região do Baixo Rio Branco (RR). Boa Vista: Embrapa Roraima, 2010.

TONINI, H.; LOPES, C. E. V.; ARAUJO, S. L. F. Caracterização do sistema extrativista e coeficientes técnicos de produção para o sistema extrativo da castanheira-do-brasil (Bertholletia excelsa H.B.K) praticado pelos indios Wai Wai em Roraima. Boa Vista: Embrapa Roraima, 2014.

VOGT, P. W. Dictionary of statistics and methodology: a nontechnical guide for the social sciences. London: Sage, 1999.

WADT, L. H. O.; KAINER, K. A.; CARTAXO, C. B. C.; NUNES, G. M.; LEITE, F. M. N.; SOUZA, J. M. L.; GOMESSILVA, D. A. P.; SOUSA, M. M. M. Manejo da castanheira (Bertholletia excelsa) para produção de castanhado-brasil. Rio Branco: Seprof, 2005.

WADT, L. H. O.; KAINER, K. A. Domesticação e melhoramento da castanheira. In: BORÉM, A.; LOPES, M. T. G.; CLEMENT, C. R. (Eds.). Domesticação e melhoramento: espécies amazônicas. Viçosa: UFV, 2009. p. 297-317.

ZUIDEMA, P. A.; BOOT, R. Demography of the Brazil nut tree (Bertholletia excelsa) in the Bolivian Amazon: impact of seed extraction on recruitment and population dynamics. Journal of Tropical Ecology. Cambridge, v. 18, n. 1, p. 1-31, abr. 2002. 


\section{Sobre as autoras:}

Julianna Fernandes Maroccolo: Mestre em Ciências de Florestas Tropicais pelo Instituto Nacional de Pesquisas da Amazônia. Engenheira Florestal pela Universidade de Brasília. Consultora no projeto "Estruturação do Observatório Castanha-da-amazônia" pelo Instituto Internacional de Educação do Brasil. E-mail: jumaroccolo@hotmail.com, Orcid: http://orcid.org/0000-0002-6268-1388

Lúcia Helena de Oliveira Wadt: Doutora em Genética e Melhoramento de Plantas pela Escola Superior de Agricultura Luiz de Queiroz. Pesquisadora da Empresa Brasileira de Pesquisa Agropecuária, na Embrapa Rondônia. E-mail: lucia.wadt@embrapa.br, Orcid: http://orcid.org/0000-0002-5018-7550

Janaína Deane de Abreu Sá Diniz: Doutora em Logística e Desenvolvimento Sustentável. Docente no Programas de Pós-graduação em Meio Ambiente e Desenvolvimento Rural e em Sustentabilidade junto a Povos e Territórios Tradicionais na Universidade de Brasília. E-mail: janadiniz@unb.br, Orcid: http://orcid.org/0000-0002-7920-5556

Kátia Emídio da Silva: Doutora em Ciências Florestais pela Universidade Federal de Viçosa e Universidade de Toronto-Canadá. Pesquisadora da Empresa Brasileira de Pesquisa Agropecuária, na Embrapa Amazônia Ocidental. E-mail: katia.emidio@embrapa.br, Orcid: http://orcid.org/0000-0003-1647-9696 
